\title{
Metodologia Para Judicializar Violaçóes de Direitos Humanos Na ORDEM JuRídica Brasileira ${ }^{1}$ \\ Rodolfo Freitas Jacarandá **
}

1 Introdução. 2 A natureza jurídica das normas de direitos humanos e os deveres do Estado. 3 Definindo violações de direitos humanos. 4 Judicialização de demandas em direitos humanos. 5 Dupla jurisdição (?). 6 Medidas de reparação. 7 Conclusão. Referências.

\section{RESUMO}

Não existe um sistema de direitos humanos na ordem jurídica interna do Brasil. Além disso, a falta de uma correta metodologia para judicializar demandas na área dificulta o reconhecimento dessas normas por juízos e tribunais, o que atrasa a busca de reparações para as violações de direitos humanos que se multiplicam pelo país - violações individuais, coletivas e sistêmicas. Proponho no artigo a seguir as bases para uma metodologia que nos permita identificar, corretamente, violações de direitos com a finalidade de utilizar o já amplo conjunto normativo em vigor para, prioritariamente, atender as vítimas de violações e reparar as falhas do Estado que dão origem, direta ou indiretamente, a essas agressões.

Palavras-chave: Direitos humanos. Metodologia. Judicialização.

\section{INTRODUÇÃO}

A ideia de direitos humanos surgiu durante os movimentos sociais do Iluminismo e ganhou força nas lutas da Revolução Francesa, quando chegou à sua forma política original: promover e defender direitos básicos e iguais, de modo universal. ${ }^{2}$

$\mathrm{O}$ desenvolvimento lento dessa ideia não esteve associado a um processo histórico didático-progressivo, como a noção de "gerações de direitos humanos" faz parecer. Em lugares diferentes e sob a pressão de intensas lutas populares, a ideia de direitos humanos adquiriu forma jurídica muito lentamente - sendo incorporada, inicialmente, nos acordos da primeira Convenção de Genebra, de 1864.

Conteúdos diversos da ideia de direitos humanos podem ser encontrados, localmente, nas constituições nacionais dos séculos XVIII e XIX, mas o fato é que a associação da forma jurídica com um sistema promotor de normas válidas, de amplo alcance, só foi realizada após a Segunda

* Professor Adjunto da Universidade Federal de Rondônia. Coordenador do Mestrado Profissional em Direitos Humanos e Desenvolvimento da Justiça, PPG/DHJUS. Membro da Comissão Nacional de Direitos Humanos do Conselho Federal da Ordem dos Advogados do Brasil (2016-2018). Vice-Presidente do Conselho Estadual de Direitos Humanos de Rondônia (2017-2018).E-mail: <rfjacaranda@uol.com.br>.https:// orcid.org/0000-0002-2047-1403 
Guerra Mundial, a partir da Organização das Nações Unidas. Mesmo assim, a história desse longo e tardio desdobramento somente passou a ganhar força político-normativa com o fim da Guerra Fria e as intervenções humanitárias decorrentes das muitas crises dos anos 1980 e 1990.

No Brasil, ainda hoje não existe um sistema, sequer um mecanismo, que permita ao indivíduo comum, de forma regular e efetiva, acionar o poder público, perante o Poder Judiciário, por violações de direitos humanos - a existência do Incidente de Deslocamento de Competência, no artigo 109, parágrafo $5^{\circ}$, da Constituição Federal, definitivamente não responde a essa demanda. ${ }^{3} \mathrm{Na}$ maioria dos casos, as normas de direitos humanos ainda são tratadas no país como diretrizes, princípios, declarações de vontade, mas não como "rights" exigíveis pelos afetados por agressões. ${ }^{4}$ Lentamente, o Poder Judiciário brasileiro assimila as normas provenientes de tratados internacionais, mas esse movimento ainda é seguido por muita desconfiança e desconhecimento. ${ }^{5}$ Grande parte desse trabalho de assimilação é feito, atualmente, pela adoção por tribunais e magistrados, de mecanismos de controle da validade das normas de direitos humanos no país, porém, na maior parte dos casos, essa aplicação é feita de forma subsidiária, raramente surgindo no ordenamento decisões fundamentadas exclusivamente em normas de direitos humanos. ${ }^{6}$ A pesquisa que deu origem a este trabalho tomou por base metodológica uma extensa revisão bibliográfica, aplicando o método comparativo revisional opondo o estado atual do sistema jurídico brasileiro às exigências de adaptação aos mecanismos existentes na ordem internacional - mecanismos tanto da Organização dos Estados Americanos (OEA) quanto do sistema da Organização das Nações Unidas (ONU). Realizei ainda uma revisão das mais recentes coletâneas de julgados no Supremo Tribunal Federal sobre direitos humanos para avaliar a relação entre aplicação primária e subsidiária das normas de direitos humanos (BRASIL, 2017).

As conclusões da pesquisa apontaram para a reconhecida lentidão de aplicação pelo Poder Judiciário das normas de direitos humanos, mas acrescento pelo menos um motivo diferente daqueles comumente reconhecidos ${ }^{7}$ - a falta de uma correta metodologia jurídica para uso e aplicação das normas de direitos humanos no Brasil. Por isso, o texto a seguir tem caráter propositivo, e o objetivo principal é de aumentar o acesso aos direitos humanos no judiciário brasileiro. Proponho, portanto, uma metodologia para utilização do vasto conjunto normativo de direitos humanos no Brasil com a finalidade de judicializar, quando for o caso, demandas de direitos humanos para analisar e julgar eventos de violações, consideradas graves ou não, individuais, coletivas ou sistêmicas.

Não defendo aqui o reconhecimento de que os direitos humanos sejam ineficazes no Brasil apenas por falta de metodologia jurídica ou de boas intenções dos aplicadores da norma. ${ }^{8}$ A consolidada história de desigualdades, corrupção e opressão que define nossa identidade não nos permite cometer equívocos quanto a isso. Argumento, contudo, que o avanço pelo qual trabalhamos depende também de clareza de propósitos específicos e de rigor jurídico.

Desse modo, na sequência, analisarei a natureza jurídica das normas de direitos humanos no Brasil (I), com a preocupação de definir melhor o significado de violação de direitos 
humanos (II). Apresentarei posteriormente uma forma de judicializar demandas em direitos humanos (III) e, a seguir, apontarei, seguindo recomendações da ONU, que medidas devem ser objeto de uma sentença em direitos humanos, com a finalidade maior de atender as vítimas de violações e de reparar as falhas da ordem jurídica que deram causa ou que favoreceram a ocorrência da violação (IV). Minhas conclusões demonstram que o aperfeiçoamento desse tipo de metodologia é fundamental para, em conjunto com o ativismo sócio-político, fortalecer os indicadores de reconhecimento, pelo poder judiciário brasileiro, da imperatividade na aplicação dessas normas no país.

\section{A NATUREZA JURÍDICA DAS NORMAS DE DIREITOS HUMANOS E OS DEVERES DO ESTADO}

As normas de direitos humanos em vigor no Brasil não são ideais abstratos registrados formalmente com a finalidade de ilustrar expectativas incertas de progresso na ordem jurídica nacional. Essas normas são comandos jurídicos válidos, gozando da mesma expectativa de produção de efeitos equivalente às demais normas (PIOVESAN, 2014; SARMENTO, 2016; RAMOS, 2016).

Essa compreensão, lenta e tardia, impõe-se na mentalidade jurídica brasileira ao custo da construção das estruturas teóricas e práticas necessárias à sua eficácia. Entretanto esse caminho não é diferente daquele percorrido por todas as áreas novas do direito, algo que ocorreu no Brasil há mais tempo com o direito do trabalho; e mais recentemente com o direito do consumidor, o direito ambiental e com o novo direito da criança e do adolescente.

O modo de funcionamento das normas de direitos humanos é diferente, contudo, de seus similares mais tradicionais. Não sendo um ramo do Direito Civil, muito menos do Direito Penal (para ficar nessas duas áreas e limitar, por hora, o escopo da discussão) as incertezas decorrentes da falta de uma correta metodologia de aplicação dessas normas atrasam sua entrada em cena de forma regular e constante na vida ordinária do sistema brasileiro de justiça.

Nos termos da Declaração de Viena, de 1993, as normas de direitos humanos foram concebidas para proteger indivíduos, grupos e coletividades inteiras contra agressões e objetivam, em primeiro lugar, impor aos Estados soberanos a obrigação de respeitar, proteger e de realizar as medidas necessárias para a defesa e a promoção dos valores e bens que formam seus conteúdos (ORGANIZAÇÃO DAS NAÇÕES UNIDAS, 1993). Embora essa concepção original tenha evoluído para proteger aqueles que são vítimas de agressões por particulares ou agentes privados, grande parte das normas de direitos humanos contém, em seu cerne, a ideia de responsabilizar os Estados pelos erros que permitiram ou não impediram que tais agressões ocorressem (ORGANIZAÇÃO DAS NAÇÕES UNIDAS, 1993).

Essas obrigações ficaram politicamente estabelecidas na Declaração Universal dos Direitos Humanos, da Organização das Nações Unidas, de 1948. Mais tarde, em 1966, elas 
foram legalmente consolidadas, por meio da Resolução 2200A da Assembleia Geral, em dois acordos para garantir a eficácia normativa da Declaração: o Pacto Internacional sobre Direitos Civis e Políticos (PIDCP - no Brasil, Decreto 592, de 6 de julho de 1992) (BRASIL, 1992b); e o Pacto Internacional sobre Direitos Econômicos, Sociais e Culturais (PIDESC - no Brasil, Decreto 591, de 6 de julho de 1992) (BRASIL, 1992c; UNITED NATIONS, 1966).

Seguindo o modelo definido no âmbito das Nações Unidas, os países do então Conselho da Europa aprovaram, em Roma, em 1950, a "Convenção Europeia dos Direitos Humanos". A Organização dos Estados Americanos, criada em 1952 (BRASIL, 1952), aprovou a sua "Convenção Americana de Direitos Humanos", em 1969, na Costa Rica. Como o texto da Convenção Americana era praticamente um tratado protetivo dos direitos civis e políticos, em 1988, foi aprovado o "Protocolo Adicional para a Convenção Americana de Direitos Humanos na área dos direitos econômicos, sociais e culturais" - concluído em São Salvador, El Salvador. No sistema ONU, o conjunto formado pela Declaração Universal e seus dois grandes tratados subsequentes passaram a ser conhecidos como "Carta Internacional de Direitos Humanos" e deram origem a uma série de outros tratados protetivos de direitos específicos (UNITED NATIONS, 1996) - o que também tem sido adotado nos sistemas regionais, como o sistema americano. Atualmente, a lista de tratados do sistema ONU que formam a "Human Rights Bill of Rights" inclui os seguintes textos: The International Convention on the Elimination of All Forms of Racial Discrimination (Decreto $\mathrm{n}^{\mathrm{O}}$ 65.810, de 8 de dezembro de 1969) (BRASIL, 1969); The International Covenant on Economic, Social and Cultural Rights (Decreto n ${ }^{\circ} 591$, de 6 de julho de 1992) (BRASIL, 1992c); The International Covenant on Civil and Political Rights (Decreto no 592, de 6 de julho de 1992) (BRASIL, 1992b); The Convention on the Elimination of All Forms of Discrimination against Women (Decreto $\mathrm{n}^{\circ} 4.377$, de 13 de setembro de 2002) (BRASIL, 2002); The Convention against Torture and Other Cruel, Inhuman or Degrading Treatment or Punishment (Decreto $\mathrm{n}^{\mathrm{o}}$ 40, de 15 de fevereiro de 1991); The Convention on the Rights of the Child (Decreto $\mathrm{n}^{\circ}$ 99.710, de 21 de novembro de 1990) (BRASIL, 1990); The International Convention on the Protection of the Rights of All Migrant Workers and Members of their Families (ainda em tramitação no Congresso brasileiro); The Convention on the Rights of Persons with Disabilities (Decreto $\mathrm{n}^{\mathrm{o}}$ 6.949, de 25 de agosto de 2009); The International Convention for the Protection of All Persons from Enforced Disappearance (Decreto n ${ }^{\circ}$ 8.767, de 11 de maio de 2016) (UNITED NATIONS, 2012a)

No caso da ordem jurídica brasileira, o país é signatário da maioria dos tratados internacionais de direitos humanos (TIDH) do sistema ONU ou do sistema OEA. Como consequência da assinatura e ratificação desses tratados, e para garantir sua validade, o país pode produzir uma legislação interna própria ou recepcionar e incorporá-los ao seu ordenamento. Para caracterizar as normas produzidas internamente como normas de direitos humanos, destaco três critérios principais: especificidade (aquelas normas aprovadas com a finalidade específica de promover a defesa dos direitos humanos); materialidade (normas cuja natureza 
material é compatível com os valores e os fins próprios às normas de direitos humanos); instrumentalidade (normas e dispositivos criados com o fim de tornar possível a defesa ou a eficácia da proteção aos direitos humanos). Enquanto o rol de TIDH's em vigor no Brasil é mais próximo de ser exaustivo, o rol de normas provenientes de processo legislativo interno é apenas sugestivo (JACARANDÁ; PATRIOTA, 2016). Diversas normas brasileiras contêm dispositivos cuja natureza de direitos humanos pode ser definida a partir de uma interpretação extensiva ou mesmo de uma justificação em razão dos fins a serem alcançados - como é o caso do Estatuto da Criança e do Adolescente e da Lei Maria da Penha, ambas as consequências da adoção, no país, de TIDH's sobre aqueles temas.

Esse processo de integração entre a ordem jurídica interna e a ordem jurídica externa é reconhecido e desejável pela Constituição de 1988, a qual determina ampla defesa e promoção dos direitos humanos como princípio da República (art. $4^{\circ}$, II), admitindo que os direitos básicos não se limitem àqueles definidos no texto constitucional, mas podem ser ampliados por meio de acordos internacionais firmados pelo país (art. 5, §2) (BRASIL, 1988).

Obedecendo a esse imperativo de integração, e em conformidade com o entendimento da Suprema Corte, a natureza jurídica das normas de direitos humanos no Brasil é definida como norma de valor supralegal, caso tenha entrado em vigor no país por meio da recepção de TIDH no ordenamento jurídico interno, estando acima das leis ordinárias e complementares; ou norma de valor constitucional, caso a norma tenha sido aprovada pelo Congresso Nacional com o rito de emenda constitucional (art. $5^{\circ}, \S 3^{\circ}$ ) (BRASIL, 2008).

Embora exista bastante divergência sobre a interpretação atual da Suprema Corte brasileira acerca das normas de direitos humanos, o conjunto normativo existente já é vasto e não existem dúvidas sobre o fato de essas normas serem obrigatórias e exigíveis, inclusive perante o Poder Judiciário, de modo que toda e qualquer restrição imposta à validade máxima de dispositivos de normas de direitos humanos em vigor no Brasil é uma violação de direitos humanos e deve ser tratada como tal.

Independentemente da possibilidade de representação internacional pelo descumprimento das obrigações assumidas em TIDH's, as normas de direitos humanos em vigor definem amplo conjunto de bens jurídicos sob tutela do Estado. Estes devem ser preservados pelos mecanismos existentes ou por outros meios que devem ser desenvolvidos.

Assim, embora o Brasil não possua um efetivo sistema interno de direitos humanos, as instituições, os órgãos executivos de Estado, o Poder Legislativo e, especialmente, o Poder Judiciário devem compreender sua função diante da tarefa de dar validade às normas atualmente ainda carentes de eficácia.

Com relação ao comportamento do Poder Judiciário a respeito da matéria importa ressaltar que a aplicabilidade das normas de direitos humanos, em ações judiciais, não é devida apenas nos casos em que há a necessidade de utilizar o controle de constitucionalidade difuso ou o controle de convencionalidade. Sobretudo, as normas internas de direitos humanos (provenientes de TIDH ou não) gozam de independência para servir de fundamento jurídi- 
co para qualquer demanda em que se busque a reparação por um direito humano violado. ${ }^{9}$ Uma forma simples de validar essa afirmação pode ser obtida da análise da coletânea de julgados temáticos do Supremo Federal, atualmente em sua terceira edição, sobre direitos humanos. Os casos em que os TIDH's são citados apenas como referências nos julgados são a quase integralidade, funcionando apenas como argumento de suporte para a utilização da legislação nacional - quando não se trata de simplesmente afastar a norma de direitos humanos, como no caso da ADPF 153, em decisão cuja relatoria foi do Min. Eros Grau. ${ }^{10}$ De toda sorte, a responsabilidade por dar efetividade às normas de direitos humanos é de cada magistrado e de cada colegiado provocado pelo advogado ou instituição representativa dos direitos individuais ou coletivos no país (Ministérios Públicos, Defensorias Públicas, Conselhos, ONG's, etc.), não sendo viável, portanto, restringir o escopo da metodologia aqui proposta à Suprema Corte.

\section{DEFININDO VIOLAÇÕES DE DIREITOS HUMANOS}

A incerteza na definição de violação das normas de direitos humanos é a principal razão teórica para afastar o reconhecimento da validade dessas normas no ordenamento jurídico brasileiro, sobretudo perante o poder judiciário. Contradições ou equívocos no estabelecimento de semelhanças entre a ideia de violação de direitos humanos e as noções de dano ou crime, provenientes do direito civil ou do direito penal, não costumam ajudar. Por esse motivo, definir precisamente o que são violações de direitos humanos é de suma importância para promover a justiciabilidade dessas normas (UNITED NATIONS, 2008a, 2008b, 2010, 2011).

$\mathrm{Na}$ medida em que os Estados devem respeitar, proteger e se esforçar para colocar em prática os compromissos assumidos em direitos humanos, é necessário monitorar os dados que podem demonstrar os problemas com relação à efetivação dessa responsabilidade. Contudo, acompanhar a implementação de compromissos em direitos humanos não significa, sempre, monitorar violações.

Há basicamente quatro formas de cumprir essa tarefa: monitorar eventos de violação; acompanhar os indicadores políticos e socioeconômicos; realizar pesquisas (survey) de opinião e percepção pública; e a realização de análises por especialistas. Cada uma dessas atividades permite avaliar os compromissos normativos assumidos pelo poder público e monitorar o seu cumprimento a partir de dois grandes planos distintos: monitorar as violações e monitorar as realizações progressivas do Estado. ${ }^{11}$

Apesar de o monitoramento das realizações progressivas por parte do poder público ser de grande relevância para compreender, inclusive, o cenário mais amplo de violações contumazes que ocorrem em determinada região ou no país como um todo, esse tipo de abordagem dificulta o monitoramento e a percepção dos episódios de violações individuais e atrasa o encontro da estatística com as vítimas que precisam de auxílio - não raro, de auxílio imediato. Assim, embora sejam tarefas complementares, o monitoramento de eventos de 
violação (events-based method) é indispensável para uma atuação prática em direitos humanos e para a obtenção de soluções para as vítimas de agressões. De acordo com o "Human Rights Indicators - A Guide to Measurement", produzido pelo Escritório para o Alto Comissariado para os Direitos Humanos das Nações Unidas:

Events-based data on human rights violations (events-based data for short) refer to qualitative or quantitative data that can be linked to events characterized by the occurrence of human rights violations. The collected information primarily describes acts of human rights violations and identifies victims and perpetrators (UNITED NATIONS, 2012a, p. 52).

Conforme a definição da ONU, violações são atos de agressão aos direitos humanos e podem ser individuais, coletivas ou sistêmicas (JACARANDÁ; PATRIOTA, 2016). Elas podem ocorrer quando há a intenção de agredir um direito (ato comissivo) ou quando quem tinha a obrigação de fazer algo para impedir a agressão foi omisso em evitá-la (ato omissivo) (UNITED NATIONS, 2012b). Normalmente, as violações são transgressões dos direitos garantidos por um sistema nacional, regional ou internacional de que o país seja parte.

O conceito de violação inclui os atos de omissão diretamente imputados ao Estado pelo fracasso em tornar eficazes as obrigações legais derivadas da legislação internacional. As violações também ocorrem quando a legislação de um país, uma política ou uma prática oficial ou costumeira se contrapõem ou ignoram obrigações assumidas pelo Estado; ou mesmo quando o Estado falha em atingir certo padrão de conduta ou um resultado específico relacionado à proteção ou à promoção dos direitos humanos. Outro tipo de violação acontece quando o Estado diminui ou elimina proteções existentes aos direitos humanos (vedação ao retrocesso) (UNITED NATIONS, 2005b).

Por essa via, importa apontar, contudo, que, tecnicamente, para fins de reconhecimento dos efeitos jurídicos da utilização do conjunto normativo de direitos humanos em vigor no Brasil, há uma distinção que deve ser aplicada na configuração de um evento de violação: a separação entre agressões aos bens juridicamente tutelados pela legislação comum (crimes e danos comuns) e as violações de direitos humanos.

Naturalmente, toda agressão a um direito atinge um bem juridicamente protegido pelas normas jurídicas em vigor no país. As instituições do sistema de justiça são competentes para evitar agressões, investigar, processar e julgar as ocorrências que não puderam ser evitadas, mas há duas hipóteses que devem ser consideradas no que concerne à necessidade de avaliar o papel do Estado para definir a existência de uma violação de direitos humanos: quando há falha de resposta do Estado, seus agentes e parceiros, ou daqueles que, agindo em seu nome, não adotam as medidas para evitar ou reparar devidamente uma agressão aos direitos humanos; ou quando há envolvimento direto de agente do Estado no evento de agressão, sobretudo daqueles que têm o dever de agir para resguardar o direito das pessoas envolvidas. Nesse segundo caso, a comprovação da falha do Estado não depende de nenhuma outra aferição (JACARANDÁ; PATRIOTA, 2016, p. 37-38). 
Essas duas hipóteses podem e devem ser tratadas como critérios para a definição do conceito de violação de direitos humanos e devem servir também para evitar que a definição de violação de direitos humanos seja tratada como crime ou dano comum. Essa é a situação, por exemplo, de um homicídio de um advogado que trabalha como defensor de direitos humanos ou uma agressão grave contra uma mulher; tais condutas já são devidamente observadas na legislação comum brasileira. No entanto, a diferença entre classificar um homicídio como crime comum ou como violação de direitos humanos depende da correta avaliação dos critérios assinalados anteriormente, ou seja, depende de averiguar se as respostas do Estado diante do ocorrido foram satisfatórias ou se houve envolvimento direto de agente do Estado na agressão.

A importância da especificidade jurídica da definição de uma violação de direitos humanos, mesmo quando a legislação nacional já inclui tal evento como crime (homicídio) ou dano (responsabilidade civil), reside na diferença de tratamento dos episódios de violação definido pelo sistema normativo próprio.

Em um primeiro momento, importa considerar que o reconhecimento da natureza jurídica dos direitos humanos no Brasil determina a prevalência dessas normas sobre a legislação comum - a denominada supralegalidade das normas de direitos humanos -, conferindo um sentido de prioridade no tratamento de violações em confronto com os crimes comuns e os danos civis e demais ilícitos ordinários. Indo além, é comum que as normas de direitos humanos determinem consequências mais duras para o tratamento de uma violação, sem esquecer o fato de que a abordagem e a investigação das condutas (exigência de provas, condução da investigação, etc.) devem seguir um caminho distinto do tradicional. ${ }^{12}$

O elemento mais importante que destaca a apuração de um evento de violação é, em regra, um processo de responsabilização que implica a discussão sobre a imposição de severas obrigações ao poder público, de forma a tentar garantir a reparação, a não repetição e a reformulação de suas práticas oficiais ou admitidas por costume ou tradição, as quais tenham dado causa à agressão em análise (Maastricht Guidelines) (UNITED NATIONS, 1997). Isso ocorre porque, inevitavelmente, até mesmo em obediência à ontologia da ideia de direitos humanos, em casos de violação, o papel do Estado está sempre em questão. ${ }^{13}$

Outro ponto que deve ser avaliado é que existem muitas condutas de violação não identificadas ainda na legislação produzida internamente, exigindo a utilização das normas oriundas de tratados internacionais, incorporadas à ordem jurídica nacional, para promover o reconhecimento de uma violação perante as autoridades políticas e judiciais nacionais.

Um último ponto que deve ser abordado com relação à definição de violação de direitos humanos diz respeito ao uso do termo "grave violação", muito comum em tratados internacionais. No sistema ONU e mesmo na maioria dos sistemas regionais, não existe coesão no uso dessa expressão. ${ }^{14}$ De certa forma, o apelo à gravidade de um evento de violação importa porque a análise desse fato pelo sistema internacional depende de certos requisitos indicadores de intensidade dos problemas em discussão. Quando as estruturas internas 
(atuação primária) falham em coibir ou reparar uma série de violações, torna-se necessário o acionamento dos mecanismos internacionais de responsabilização (atuação subsidiária). Desse modo, embora toda agressão a um direito humano seja uma violação, somente seriam alvo de atenção dos organismos internacionais aquelas violações mais graves, cuja escala e intensidade merecem apreciação pelo tamanho da ameaça que representam para a capacidade de reação do Estado de origem do fato (LEACH, 2010). No caso da ONU, os critérios mais usados para definir "graves violações" de direitos humanos são o caráter ou a especialidade do direito atingido, a magnitude da violação, o tipo de vítima, o impacto da violação (UNIVERSITÉ DE GENÈVE, 2014).

No caso do sistema da OEA, considera-se a gravidade de uma violação na proporção em que se avalia a natureza das responsabilidades do Estado em que ocorreu a violação, ou seja, o tamanho e a intensidade das falhas estatais que deveriam impedir os episódios de violação. Entre os critérios para definir o fator de gravidade na CIDH estão a tendência à repetição das violações na mesma região ou em outras partes do território do Estado, o número de vítimas atingidas, a hierarquia das autoridades envolvidas e o risco de as condutas sob julgamento representarem uma forma oficial de ação do Estado, em vez de leniência, subdesenvolvimento ou outros erros não intencionais (algo verificado no julgamento da Lei de Anistia do Brasil) (COMISSÃO INTERAMERICANA DE DIREITOS HUMANOS, 2009)

No Brasil, embora não exista um sistema próprio de direitos humanos, a Emenda Constitucional 45, de 2004 (BRASIL, 2004), criou, no artigo 109, parágrafo 5º da Constituição da República, o Incidente de Deslocamento de Competência, também chamado de federalização; tal procedimento autoriza o deslocamento da competência para investigar, processar e julgar um fato da justiça estadual para a justiça federal, em casos de grave violação de direitos humanos. O Superior Tribunal de Justiça tem considerado o reconhecimento de gravidade da violação um somatório de certo nível de intensidade da agressão analisada com a comprovada incapacidade de o Estado-membro efetivar a correta prestação jurisdicional.

Entendo que, embora o uso da expressão "grave violação" possa fazer sentido ao analisar, comparativamente, as ações de intervenção em larga escala, como genocídios ou equivalentes, ela não tem muita utilidade diante da necessidade de estabelecer critérios rigorosos que sirvam de gatilho para a utilização da metodologia de monitoramento e processamento de uma violação em todos os casos, dentro da ordem jurídica interna. Assim, diante desse imperativo, estando presentes a agressão ao direito específico mais a falha do Estado, penso ser o bastante para acionar a metodologia de processamento da demanda em direitos humanos.

\section{JUDICIALIZAÇÃO DE DEMANDAS EM DIREITOS HUMANOS}

A confusão com relação às normas de direitos humanos se manifesta, sobretudo, no Brasil, pelo abandono da validade desses mesmos direitos. Na prática judicial cotidiana, não há, salvo pequenas exceções, consequência alguma decorrente da classificação de uma conduta como violação de direitos humanos. 
Apesar de todos os órgãos dos três poderes do Estado serem responsáveis pela efetivação dos direitos humanos, quando o acionamento de medidas políticas ou administrativas é ineficaz o recurso ao poder judiciário se transforma na única oportunidade real de obter uma tomada de decisão capaz de pôr fim ou reparar uma violação.

Embora a unidade do Estado não possa ser negada com a finalidade de evitar a responsabilização diante de uma violação de direitos humanos, a busca por medidas de resposta deve obedecer à organização interna do Estado e à sua distribuição constitucional de competências para atuação em cada caso, não sendo admissível, contudo, que essa organização funcione para impedir que uma violação comprovada fique sem resposta.

A incapacidade de um órgão ou mesmo de um poder do Estado para atuar em um caso de violação de direitos humanos não pode servir de mecanismo ordinário para inviabilizar a responsabilização pelas medidas de contenção ou reparação de uma violação. A rigor, dependendo da forma como essa incapacidade se manifesta, ela mesma pode significar uma violação de direitos.

Em situações corriqueiras, no direto civil ou mesmo no direito penal, o mecanismo causa-responsabilidade atua para estabelecer a correta cadeia de respostas a um fato que atinge determinado direito, mas, por exemplo, quando autoridades do poder público divergem sobre a responsabilização por danos provocados pela má gestão de recursos destinados ao sistema prisional, as vítimas de um processo sistêmico de violações não podem ficar à margem de qualquer ação de socorro ou de reparação porque as normas em vigor no país impõem ao governo estadual o dever de zelar pelos presídios, e o governo local em questão não tem condições de agir. Considerando uma forma de atuar orientada pela perspectiva das vítimas de violações (victim-oriented perspective), nos termos da Resolução 60/147, da Assembleia Geral da ONU, a busca por responsabilização deve ter início a partir das normas que organizam o Estado para esse fim, mas, nos casos em que os degraus iniciais dessa cadeia falham, é necessário procurar as condições para intervenção em qualquer outra instância em que elas possam ser encontradas ${ }^{15}$ - mesmo que, para isso, seja necessário recorrer ao poder judiciário (UNITED NATIONS, 2003, 2005a, 2006; ROTHENBURG, 2014). Esse é o sentido do instituto contido no artigo 25 da Convenção Americana de Direitos Humanos, ao afirmar que:

Artigo 25 - Proteção judicial. 1. Toda pessoa tem direito a um recurso simples e rápido ou a qualquer outro recurso efetivo, perante os juízes ou tribunais competentes, que a proteja contra atos que violem seus direitos fundamentais reconhecidos pela constituição, pela lei ou pela presente Convenção, mesmo quando tal violação seja cometida por pessoas que estejam atuando no exercício de suas funções oficiais (BRASIL, 1992a, online).

Em razão do respeito à organização interna do Estado, com a finalidade de utilizar corretamente os recursos existentes para obter o remédio devido a uma ou mais vítimas de uma violação, é que surgiu o instituto do esgotamento das vias internas como condição para acionamento das cortes internacionais. Pela regra, os postulantes, perante cortes internacionais, precisam comprovar que tentaram a satisfação do direito violado em todas as instâncias 
nacionais disponíveis. Esse critério é uma forma de relacionamento entre a ordem jurídica nacional e a ordem jurídica internacional, de modo que as duas devem ser vistas como complementares, sem que seja estimulada a pretensão de utilizar um dispositivo da ordem externa em pura e simples substituição da autoridade interna (JACARANDÁ; PATRIOTA, 2016). No que concerne especificamente aos direitos humanos, essa regra passou a produzir consequências jurídicas no Brasil após a Emenda Constitucional 45, de 2004 (BRASIL, 2004), com a adição do parágrafo $5^{\circ}$ ao artigo 109 da Constituição da República, criando o instituto do Incidente de Deslocamento de Competência (IDC). Embora não inove a regra do esgotamento das vias internas (nesse caso, relativas ao Estado-membro da Federação), a atuação do Superior Tribunal de Justiça, em pedidos de deslocamento, reforça a noção de que os três poderes são responsáveis por atuar, remediar violações e reparar as vítimas.

Apesar de ter havido muita expectativa com relação ao funcionamento do IDC, o fato é que o mecanismo se revelou inepto para criar uma espécie de sistema judicial interno de direitos humanos. Fora a pouca utilização, a criação do IDC contribuiu ainda para solidificar a crença de que as causas em direitos humanos devem ser apreciadas pela justiça federal.

A atribuição de competência para julgamento de qualquer demanda em direitos humanos pela justiça federal é um erro, e não há referências específicas sobre esse tema nas normas em vigor no Brasil. Existe uma proposta de emenda à Constituição tramitando na Câmara dos Deputados - PEC 368/1996 (BRASIL, 1996) - propondo essa matéria, mas está parada desde 2000. Esse engano desconsidera que as normas jurídicas de direitos humanos provenientes de tratados internacionais ou de dispositivos internos contêm institutos e direitos materiais. Assim, a proteção e a eficácia desses institutos dependem de todas as esferas judiciais - justiça especial ou comum, estadual ou federal.

Então, diante de um caso concreto de violação de direitos humanos, dois critérios poderiam ser utilizados para resolver eventuais conflitos de competência: a) a especialidade de um dispositivo legal determina, diretamente, a forma de proceder para escolher o juízo perante o qual a demanda será proposta. Esse é o caso de normas que estabelecem ou criam seus próprios mecanismos de fiscalização e controle, bem como direcionam as reclamações por violações daquele direito à determinada instância específica; b) por analogia, é possível encontrar as respostas para casos ambíguos ou equívocos nos institutos jurídicos da ordem vigente. Por exemplo, os casos de agressões contra indígenas, seu território e sua cultura devem ser julgados pela justiça federal, o que não deve ocorrer quando se tratar de reparação civil em casos de tortura que tenham por fundamento jurídico do pedido o Decreto 40, de 15 de fevereiro de 1991 (que promulgou a Convenção Contra a Tortura) (BRASIL, 1991) - excetuando-se as definições específicas contidas na legislação.

É necessário levar em consideração que, apesar de toda violação ser definida a partir do estabelecimento correto da fórmula "quem fez o que a quem" (who did what to whom), nem sempre será o caso de uma demanda judicial em direitos humanos buscar atingir o objetivo de punir um agente agressor específico (JACARANDÁ; PATRIOTA, 2016, p. 65). ${ }^{16}$ 
foco das ações de direitos humanos raramente deve ser a identificação e a punição dos agressores - competência específica das ações e dos órgãos da justiça criminal. No Brasil, por exemplo, em casos de abuso de autoridade ou de tortura cometidos por agentes públicos, um advogado de uma organização não governamental não poderia, manejando as normas de direitos humanos, substituir o Ministério Público em suas competências para decidir processar ou não os acusados por esses crimes. No entanto, seria viável conceber um caminho, diante do caso concreto, que levasse a organização em tela a postular, com base nos direitos humanos, formas distintas de reparação para as vítimas ou mesmo a reformulação de uma ou mais práticas oficiais que deram causa, direta ou indiretamente, aos episódios de violação em análise.

Por fim, com relação aos requisitos necessários para judicializar demandas em direitos humanos, uma questão que ainda é alvo de muitas dúvidas diz respeito à legitimidade ativa. Aqui o critério da analogia citado anteriormente é o melhor guia, sobretudo na utilização das ferramentas do processo civil para decidir tipos de ações, juízos processantes e outros instrumentais necessários para formalizar as demandas. É comum encontrar ativistas que exijam o reconhecimento de que advogado de particular possa mover uma ação civil pública em matéria de direitos humanos, mas esse clamor é pouco realista. Melhor seria optar pela via da representação contra eventual omissão do Ministério Público em face do dever de agir e caracterizar essa omissão como uma violação de direitos humanos, exigindo que o expediente fosse analisado à luz da importância da legislação específica e da gravidade da inércia então comprovada. Na maior parte dos casos, o que se deve buscar é a imperatividade do comando normativo de direitos humanos na práxis judicial ordinária, caracterizando a supralegalidade ou a inequívoca constitucionalidade da norma, requerendo do juízo que reconheça a validade que a ela é devida.

\section{DUPLA JURISDIÇÃO (?)}

A metodologia aqui apresentada exige a identificação de uma agressão a um direito protegido pelo conjunto normativo específico, uma falha do Estado e/ou o envolvimento de um agente público para configurar uma violação de direitos humanos.

Não se tratando de uma demanda de direito civil ou penal, as ações de direitos humanos não buscam a mesma finalidade daquelas, ou seja, não objetiva levar à prisão um agressor ou obter a mera recomposição do dano provocado pelo eventual agressor identificado. Esses não são resultados impossíveis diante de um caso de violação, mas a metodologia específica para lidar com direitos humanos não invade a esfera do direito penal ou do direito civil.

Se, em determinado crime de tortura, o agente agressor for corretamente identificado, processado e punido pela justiça criminal e a vítima for socorrida, amparada e indenizada pela justiça civil, tudo ocorrendo em prazo razoável, nesse cenário, em tese, não haveria demanda de direitos humanos a ser proposta porque as respostas da ordem jurídica interna foram aceitáveis diante do ocorrido. Enxergo, contudo, a possibilidade de uma Ação de Direitos 
Humanos contra o Estado no caso citado: caso falhas graves tenham ocorrido nas estruturas existentes para impedir a tortura (segurança, fiscalização, etc.). Em tais circunstâncias, não há garantias de que o julgamento criminal do réu envolva recomendações ou determinações para a correção dessas falhas. Assim, com a finalidade de inibir comportamentos futuros e obter providências mais amplas, uma ação específica pode ser proposta. Tenho dúvidas sobre a utilidade e a conveniência de tratar um julgamento criminal de abuso de autoridade ou de um homicídio como um julgamento de direitos humanos, mesmo que se trate de um caso que configure típica afronta aos direitos humanos. Talvez seja útil apelar para as normas de direitos humanos com a finalidade de exigir do Estado julgamento rápido e eficiente de certa demanda, para evitar outras formas de responsabilização, em razão da inércia ou omissão, ou de algo semelhante. ${ }^{17}$

Cenários assim são mais claramente identificáveis quando as violações se repetem e as falhas se acumulam, configurando as violações coletivas ou sistêmicas, ensejando a necessidade de ações de direitos humanos que tenham por objetivo o atendimento às vítimas e a correção imediata das falhas estatais - falhas que podem ser configuradas também pela soma de atos omissivos ou comissivos do poder público e dos seus agentes, o que pode envolver desde um agressor direto a um gestor corrupto. Como o que se espera de uma demanda judicial de direitos humanos nunca será o que se espera de uma típica ação penal, por exemplo, a busca pela mediação social ou por outras formas de solução para o conflito é bastante desejável, dentro ou fora do processo, sobretudo porque o Brasil não é reconhecido por ter um poder judiciário ágil e eficiente. Medidas políticas ou administrativas que atendam à finalidade de socorrer as vítimas e recompor as falhas estatais que incidiram ou deram causa à violação (o que inclui ações administrativas contra os agentes públicos agressores) podem conferir satisfação à busca pelo direito de modo mais rápido e prático do que uma decisão judicial, comumente mais lenta e onerosa para as partes.

A judicialização, contudo, não deve ser evitada em troca da expectativa da boa vontade do poder público, sobretudo quando as fases negociais promovidas em instâncias administrativas ou órgãos, como conselhos e congêneres, já tenham consumido relevante tempo das vítimas. Importa lembrar que, por disposições da própria Convenção Americana de Direitos Humanos, a lentidão na apreciação de um caso de violação pelo governo ou pelo poder judiciário, tornando quase impossível o socorro às vítimas ou inútil uma eventual reparação, também pode configurar uma violação, autorizando a quebra da regra do esgotamento das vias internas.

Um capítulo importante dessa discussão surge com a avaliação da possibilidade de considerar o poder judiciário um agressor dos direitos humanos quando erros de seus membros não são avaliados e corrigidos adequadamente. Essa opção é, no Brasil, uma ameaça para o funcionamento da metodologia aqui proposta porque não cabe ao poder executivo corrigir os erros do judiciário quando os órgãos de controle não forem diligentes para fazê-lo. 
Esse imbróglio chegou à Corte Interamericana de Direitos Humanos em um julgado paradigmático (Caso Gomes Lund e outros) contra o Brasil que implicou a determinação para o afastamento da validade da Lei da Anistia no país - Lei n 6.683/1979. Nesse episódio, o Supremo Tribunal Federal já havia se manifestado contrariamente a essa posição na Ação de Descumprimento de Preceito Fundamental n. 153, em 2010, ação proposta pelo Conselho Federal da Ordem dos Advogados do Brasil. Está pendente de solução a decisão do estado brasileiro sobre o cumprimento da decisão internacional e da separação de poderes na organização da república brasileira, tendo em vista que o chefe do Estado não pode impor à Corte Suprema a obrigação de aceitar a sentença internacional, ou mesmo afastar a validade da decisão suprema interna por ato político - tal expediente somente seria aceitável por decisão da própria Corte. ${ }^{18}$

\section{MEDIDAS DE REPARAÇÃO}

Como em qualquer outra área do direito, violações de direitos humanos ferem direitos que devem ser reparados administrativa, política ou judicialmente, por sua natureza, os direitos humanos demandam medidas de reparação (right to a remedy) que devem ter duas finalidades distintas, em ordem de prioridade: atender às vítimas de violações; corrigir as falhas da ordem jurídica que permitiram que as violações ocorressem.

As medidas de reparação estão espalhadas pela legislação internacional de direitos humanos e de direito internacional humanitário e de conflitos armados. Essas determinações formam um conjunto de recomendações compiladas na Resolução 60/147 (UNITED NATIONS, 2005a), da Assembleia Geral da ONU, citada anteriormente.

Não há motivos para não interpretar tais dispositivos normativos como comandos imperativos, afinal, a imperatividade é um dos os efeitos naturais de uma jurisdição que o Brasil aceitou compor. Utilizo as determinações da ONU como exemplo, sem esquecer, contudo, que os mesmos comandos estão contidos no sistema regional da OEA, expostos de forma bastante semelhante na Convenção Americana e nos demais documentos legais internacionais.

Dessa forma, seguindo a Resolução 60/147 (UNITED NATIONS, 2005a) como modelo, com a finalidade de cumprir a obrigação de respeitar, garantir o respeito e implantar a máxima proteção aos direitos humanos, o país precisa, além de incorporar os TIDH's à sua ordem jurídica (II, $3^{\circ}$, a), adotar medidas para garantir o acesso igualitário, efetivo e rápido à justiça (II, $\left.3^{\circ}, \mathrm{b}\right)$; tornar disponível para as vítimas de violações os remédios adequados, efetivos e rápidos, incluindo medidas de reparação (II, $3^{\circ}$, c) e assegurar que a legislação interna seja capaz de prover, pelo menos no mesmo nível, proteção às vítimas como determinado pelas obrigações internacionais (II, $3^{\circ}, \mathrm{d}$ ).

No que concerne aos cuidados específicos com as vítimas de violações, os remédios devem incluir: efetivo e igualitário acesso à justiça (VII, 11, a); adequada, efetiva e rápida reparação pelos prejuízos sofridos (VII, 11, b) e acesso às informações relevantes que dizem 
respeito às violações e aos mecanismos de reparação (VII, 11, a). Importa lembrar que, no sistema da ONU, por muito tempo, a única medida obtida após uma revisão positiva de um caso apresentado à antiga Comissão de Direitos Humanos (extinta em 2006) era publicar o veredito contra o Estado agressor (também conhecido como princípio naming and schaming apontar e envergonhar). Embora a medida não fosse muito eficaz, é sempre válido considerar que é tradicional dos casos de violação de direitos humanos o esforço, por parte de autoridades do Estado, para fugir à responsabilização por seus crimes, tornando o reconhecimento público importante para a satisfação da justiça. ${ }^{19}$

A citada Resolução ainda inclui como medidas de reparação ao sofrimento das vítimas: a restituição, na medida do possível, ao estado anterior à violação; a compensação pelos danos, proporcional à gravidade da violação; a reabilitação social, médica, psicológica e jurídica, às expensas do poder público; a satisfação da verdade e da justiça, para cessar as violações ainda em andamento, identificar corretamente todas as vítimas, os agressores, assim como declarar, oficialmente, o ocorrido de modo a ajudar na recuperação da dignidade das vítimas e das pessoas próximas a elas. Isso inclui, dentre outros, apologia pública, reconhecimento dos fatos e aceitação das responsabilidades; a garantia de não repetição, o que abrange o controle sobre as forças armadas e de segurança pública, o fortalecimento do poder judiciário e a proteção aos profissionais que atuam na defesa de direitos humanos, bem como a revisão e a reformulação da legislação que contribuem ou permitem a ocorrência de violações (IX, 19 a 23).

Todas essas medidas são perfeitamente aplicáveis por juízos singulares ou colegiados de qualquer instância do poder judiciário brasileiro, em decorrência da análise de um caso de violação, respeitados os institutos processuais vigentes e suas regras específicas de competência e legitimidade ativa e passiva, desde que sejam manejadas as ações próprias para tal fim. Basta, para isso, o reconhecimento da imperatividade das normas existentes no país e a aplicação da metodologia exposta acima, seguindo os critérios de especialidade e analogia, conforme explicado anteriormente.

Não diviso a hipótese de assumir que ações criminais possam cumprir as finalidades expostas acima, por vários motivos, mas deixarei essa reflexão para outro momento. É inegável, naturalmente, que a falta de responsabilização criminal de agentes públicos ou privados por agressões aos direitos humanos reforce o cenário de perpetuação das violações. Também reconheço que é possível, no âmbito de uma Ação Penal Pública, tomar uma decisão que não apenas condene o réu, mas produza efeitos sobre sua instituição de origem. Meu argumento, contudo, insiste na necessidade de responsabilizar a organização jurídico-política interna, por meio dos mecanismos judiciais existentes, adaptando-os conforme a metodologia apresentada, seja utilizando as ações constitucionais, como o Habeas Corpus, o Mandado de Segurança, o Direito de Petição, o Direito de Representação e as Ações de Controle de Constitucionalidade, seja utilizando outros procedimentos, como a Ação Civil Pública e congêneres. 


\section{CONCLUSÃO}

A justiciabilidade das normas de direitos humanos no Brasil é um tema recente, mas, apesar de o país ser contumaz descumpridor dos acordos que assina em direitos humanos, essa discussão não é isolada. Ainda hoje, mundo afora, há muito embate acadêmico sobre o papel das normas de direitos humanos, e muitos intelectuais tendem a compreender os direitos humanos mais como um padrão moral para a civilização (BEITZ, 2009), um programa político-moral para povos bem-ordenados (RAWLS, 2001) ou um conjunto de mecanismos que servem para quebrar a imunidade da soberania dos Estados em casos de grave ruptura da ordem institucional interna (RAZ, 1986), e não como direitos justiçáveis.

O vasto conjunto normativo de direitos humanos já existente no Brasil não deixa dúvidas, contudo, sobre sua natureza e finalidade.

Não raro, essa certeza esbarra nas dificuldades de entendimento do assunto manifestada por apoiadores dessa ideia que a festejaram logo após o citado julgamento pelo STF do caso que afastou a validade da prisão do depositário infiel no Brasil, em respeito a dispositivos da Convenção Americana de Direitos Humanos. Muitos autores, como Valério Mazzuoli e Luís Flávio Gomes, propalaram, naquele momento, de modo um tanto fantasioso, uma nova era para os direitos humanos no Brasil e uma mudança na própria natureza do Estado constitucional brasileiro (MAZZUOLI, 2009; GOMES, 2008).

A esse conjunto de reações, um tanto sem sentido, somam-se as reações referentes à aprovação do parágrafo terceiro do artigo quinto da Constituição da República, em 2004. À época, muito se festejou uma nova era para os direitos humanos no Brasil - no momento exato em que, na verdade, ao adicionar a exigência de quórum de emenda constitucional para incorporar ao texto magno texto de TIDH, os legisladores brasileiros estavam impondo obstáculos à validade do parágrafo segundo do mesmo artigo, cuja redação abria a possibilidade de que isso acontecesse, sem a votação pelo rito difícil das emendas (conforme a importante lição de Francisco Rezek) (REZEK, 2000).

Não pretendo afirmar que a falta de reconhecimento das normas de direitos humanos pelo poder judiciário brasileiro se dê, unicamente, pela ausência de uma coerente estrutura metodológica para orientar a judicialização de demandas na área - composta, basicamente, pelo dever de apontar a agressão e as falhas do Estado. O que proponho é um diagnóstico: havendo essa lacuna na ordem jurídica brasileira, as dificuldades para lidar com o conjunto normativo de direitos humanos se acentuam.

O principal motivo para que as normas de direitos humanos não tenham validade social (simplificando, nos termos de Kelsen (1998), significando falta de eficácia ou falta de capacidade de produzir efeitos sociais e judiciais) é a subjugação da socialização brasileira às estruturas de poder desiguais e injustas e ao modo como as relações de poder no país se organizam para se proteger dos avanços e das mudanças. Impedir os avanços em direitos humanos faz parte da luta contra a criação de uma verdadeira república democrática, justa e plural. 
Esse argumento, mesmo reconhecendo as causas político-sociais desse atraso, é absolutamente essencial para aumentar a pressão sobre o poder judiciário pelo reconhecimento cotidiano e ordinário do uso das normas de direitos humanos, e não é possível obter sucesso nessa estratégia sem uma metodologia adequada para judicializar, se for o caso, violações de direitos humanos.

As dificuldades enfrentadas para conferir eficácia ao incidente de deslocamento de competência dão testemunho da resistência em julgar as falhas do Estado, mas julgar órgãos e agentes públicos é uma realidade no judiciário brasileiro, e acrescentar violações de direitos humanos a esse rol de possibilidades não causaria tanto impacto técnico aos serviços ordinariamente prestados aos jurisdicionados.

Aqui reside outro argumento favorável à metodologia aqui apresentada: permitir que o jurista comum, e não apenas o Ministério Público, a Defensoria Pública ou outros agentes do Estado possam fiscalizar e demandar contra esse mesmo Estado em ações de direitos humanos.

O IDC é um instrumento politizado demais, instaurado sob avaliação de conveniência do Procurador Geral da República, nomeado pelo Presidente da República. Assim como ocorre com a Corte Interamericana de Direitos Humanos, o IDC sofre muita expectativa para pouquíssima realização.

O controle sobre a validade e a eficácia das normas de direitos humanos não deve ficar submetido a uns poucos agentes, responsáveis por analisar apenas as "grandes", "severas" ou "massivas" violações. Essa atribuição deve estar disponível a qualquer interessado que queira fazer uso do direito para coibir, reprimir ou reparar violações de direitos humanos, em qualquer circunstância.

\title{
METHODOLOGY TO PROSECUTE VIOLATIONS OF HUMAN RIGHTS IN THE BRAZILIAN LEGAL SYSTEM
}

\begin{abstract}
There is no human rights system in Brazil's domestic legal order. In addition, the lack of a correct methodology to prosecute demands in the area makes it difficult to recognize these norms by judges and courts, which creates many obstacles to the search for reparations for human rights violations that multiply across the country. I propose in the following article the basis for a methodology that allows us to correctly identify violations of human rights with the purpose of using the already existing normative set up to prioritize the victims and to repair the faults of the State that give rise, directly or indirectly, to these aggressions.
\end{abstract}

Keywords: Human rights. Methodology. Prosecute. 


\section{METODOLOGÍA PARA JUDICIALIZAR VIOLACIONES DE DERECHOS HUMANOS EN EL ORDENAMIENTO JURÍDICO BRASILEÑO}

\section{RESUMEN}

No existe un sistema de derechos humanos en el ordenamiento jurídico interno de Brasil. Además, la falta de una correcta metodología para judicializar demandas en el área dificulta el reconocimiento de esas normas por juicios y tribunales, lo que retrasa la búsqueda de reparaciones para las violaciones de derechos humanos que se multiplican por el país violaciones individuales, colectivas y sistémicas. Propongo en el artículo a seguir las bases para una metodología que nos permita identificar correctamente violaciones de derechos con la finalidad de utilizar el ya amplio conjunto normativo en vigor para, prioritariamente, atender a las víctimas de violaciones y reparar las fallas del Estado que dan origen, directa o indirectamente, a esas agresiones.

Palabras clave: Derechos humanos. Metodología. Judialización.

1 Este trabalho é resultado de uma pesquisa conduzida por mim, na Universidade Federal de Rondônia, por três anos, cujos resultados parciais, em outro formato, resultaram na publicação - com a colaboração dos membros da Comissão Nacional de Direitos Humanos, 2013-2015 - pelo Conselho Federal da Ordem dos Advogados do Brasil, por meio de sua Comissão Nacional de Direitos Humanos, de um "Manual Prático para Atuação em Direitos Humanos", que pretende orientar juristas e ativistas para enfrentar o desafio de lutar pela consolidação dos direitos humanos como ramo efetivo do direito na ordem jurídica interna.

2 Para uma revisão do contexto histórico-jurídico do surgimento da ideia de direitos humanos, conferir: Freeman (2002), Hunt (2009) e Moyn (2010).

3 Conferir Abboud (2017) e Ramos (2004).

4 Ferreira e Mezzaroba (2018), em artigo recente, demonstram essa fragilidade com relação ao poder judiciário brasileiro e revisam a forma como ela repercute no direito eleitoral. Em estudo semelhante, mas aplicado aos temas de direito ambiental conferir Silva Filho (2014). Corroboram ainda o mesmo raciocínio Ramos (2009) e Moreira (2015).

5 Conferir: Piovesan (2014), Maués e Magalhães (2016) e Ramos (2016).

6 Conferir: Sarlet (2013) e Sarmento (2016).

7 Flávia Piovesan lista alguns desses desafios (PIOVESAN, 2014).

8 Entre os trabalhos publicados no Brasil recentemente sobre esse tema recomendo fortemente a leitura de Cunha (2005). O trabalho do professor José Ricardo Cunha é um exemplo de uma forma de investigar a compreensão sobre a justiciabilidade dos direitos humanos que precisa ser mais difundida e aplicada em todo o país.

9 Sobre o tema da justiciabilidade e do comportamento do poder judiciário com relação às normas de direitos humanos, conferir: Cunha (2005) e Melo (2006).

10 Cito com exemplo os seguintes casos: RE 575.144; Inq 3.412 ED; RE 477.554 AgR; ADI 4.277; Pet 3.388 ED; Pet 3.388; ADI 3.540 MC; RHC 121.835 AgR; ADI 1.800; ARE 639.337 AgR; RE 248.869; MS 33.864; RMS 27.840. Em contrário, configurando exemplo de efetiva utilização das normas de direitos humanos: ADI 3.937 MC, rel. min. Marco Aurélio, voto do min. Joaquim Barbosa, j. 4-6-2008, P, DJE de 10-10-2008; ADPF 347 MC, rel. min. Marco Aurélio, j. 9-9-2015, P, DJE de 19-2-2016 (BRASIL, 2017, p. 75). 
11 O Human Rights Information and Documentation Institute - HURIDOCS tem sua sede em Genebra, na Suíça e atua em vários países do mundo auxiliando a catalogar e a processar informações sobre violações de direitos humanos. A metodologia desenvolvida pelo Instituto é usada pela ONU. Conferir: Guzman e Verstappen (2001) e Guzman, Verstappen e Dueck (2001).

12 Esse tema é bastante complexo e pouco estudado no Brasil, no âmbito dos cursos de formação jurídica ou de especialização da atividade judicial. Para mais informações sobre metodologia de monitoramento e investigação de violações de violações de direitos humanos, conferir: (UNITED NATIONS, 2001; GUZMAN; VERSTAPPEN, 2001; GUZMAN; VERSTAPPEN; DUECK, 2001; MAHLUM, 2006; JACOBSEN, 2008).

13 Estudos como os de Ruotti et al. (2009), ajudam muito a entender como a soma de violações individuais e coletivas se transformam em violações sistêmicas em larga escala (pobreza, falta de acesso à saúde etc.

14 Penso que a utilização de termos como "grave", "massiva”, "severa” ou outros qualificativos tenha a ver mais com a necessidade de justificar a seriedade das medidas de intervenção internacional na soberania de um Estado violador do que com a rigorosa categorização do conceito de violação. Na ordem jurídica interna, satisfeito os critérios expostos anteriormente, não vejo muitos motivos para usar medidas de intensidade para definir o conceito. Conferir: Université de Genève (2014).

15 As referências na legislação internacional em relação à necessidade de uma atuação concentrada no socorro às vítimas de uma violação são vastas. Para citar algumas: Declaração Universal, artigo $8^{\circ}$; artigo $2^{\circ}$ do Pacto Internacional dos Direitos Civis e Políticos; artigo $6^{\circ}$ da Convenção Internacional para a Eliminação de Todas as Formas de Discriminação Racial; artigo 14 da Convenção contra a Tortura e Outros Tratamentos Cruéis, Desumanos e Degradantes; artigo 39 da Convenção sobre os Direitos da Criança.

16 A própria ONU passou a utilizar como base a metodologia desenvolvida pelo Instituto Suíço Huridocs (Human Rights Documentation and Information). Utilizei esses estudos como referência para desenvolver a ideia de violação dentro da ordem jurídica brasileira. Para conhecer melhor o trabalho da rede Huridocs, acesse: <https://www.huridocs. org > ; <https://www.huridocs.org/research-development >; <https://www.huridocs.org/resource/micro-thesauri>;

17 Uma observação importante sobre os casos de tortura: o principal motivo para desqualificar acusações de tortura é a falta de comprovação do elemento subjetivo do tipo, ou seja, a intenção de impor dano para castigar ou obter informações. Operando com normas de direitos humanos, a identificação da vítima e a comprovação do dano, com envolvimento de agente público ou sob a custódia do Estado, já seriam o bastante para montar um caso com boas expectativas de sucesso para impor ao Estado (Estado-membro, município ou União) a obrigação de reparação e as demais medidas. Nessa situação, mesmo sem a identificação dos agentes, apenas com a comprovação de o fato ter ocorrido sob a custódia do Estado, já seria possível configurar a violação por tortura e responsabilizar o Estado. Não haveria, então, uma Ação Criminal clássica, mas uma demanda em direitos humanos.

18 Conferir: Peterke (2009) e Ramos (2013).

19 Penso ser esse um dos motivos, dentre vários outros, pelos quais o IDC se tornou tão inepto, afinal, é inevitável que o STJ, para acolher o incidente, reconheça, formalmente, a incapacidade do Estado-membro para lidar com os eventos de violação em análise, o que em muito ameaça a solidez do pacto federativo, especialmente em um país em que esse pacto já é sustentado de maneira bastante superficial.

\section{REFERENNCIAS}

ABBOUD, Georges. Controle de convencionalidade e direitos fundamentais. Revista de Processo, São Paulo, v. 268, p. 569-584, jun. 2017.

BEITZ, Charles. The Idea of Human Rights. New York: Oxford University Press, 2009.

BRASIL. Câmara dos Deputados. Decreto no 30.544, de 14 de fevereiro de 1952. Promulga a Carta da Organização dos Estados Americanos, firmada em Bogotá, a 30 de abril de 1948. Câmara, Brasília, DF, 1952. Disponível em: <http://www2.camara.leg.br/legin/fed/decret/1950-1959/decreto-30544-14-fevereiro-1952-340000-publicacaooriginal-1-pe.html>. Acesso em: 6 maio 2018. 
. Câmara dos Deputados. Decreto n. 65.810, de 8 de dezembro de 1969. Promulga a Convenção Internacional sobre a Eliminação de todas as Formas de Discriminação Racial. Câmara, Brasília, DF, 1969. Disponível em: <http://www2.camara.leg.br/legin/ fed/decret/1960-1969/decreto-65810-8-dezembro-1969-407323-publicacaooriginal-1-pe. html>. Acesso em: 6 maio 2018.

. Constituição da República Federativa do Brasil de 1988. Presidência da República, Brasília, DF, 1988. Disponível em: < http://www.planalto.gov.br/ccivil_03/constituicao/constituicao.htm >. Acesso em: 6 maio 2018.

. Decreto no 99.710, de 21 de novembro de 1990. Promulga a Convenção sobre os Direitos da Criança. Presidência da República, Brasília, DF, 1990. Disponível em: $<$ http://www.planalto.gov.br/ccivil_03/decreto/1990-1994/D99710.htm>. Acesso em: 6 maio 2018.

. Decreto no 40, de 15 de fevereiro de 1991. Promulga a Convenção Contra a Tortura e Outros Tratamentos ou Penas Cruéis, Desumanos ou Degradantes. Presidência da República, Brasília, DF, 1991. Disponível em: <http://www.planalto.gov.br/ccivil_03/ decreto/1990-1994/D0040.htm >. Acesso em: 6 maio 2018.

. Decreto $n^{\circ}$ 678, de 6 de novembro de 1992. Promulga a Convenção Americana sobre Direitos Humanos (Pacto de São José da Costa Rica), de 22 de novembro de 1969. Presidência da República, Brasília, DF, 1992a. Disponível em: <http://www.planalto.gov. br/ccivil_03/Decreto/D0678.htm >. Acesso em: 06 de maio de 2018.

. Câmara dos Deputados. Decreto n. 592, de 6 de julho de 1992. Atos Internacionais. Pacto Internacional sobre Direitos Civis e Políticos. Promulgação. Câmara, Brasília, DF, 1992b. Disponível em: <http://www2.camara.leg.br/legin/fed/ decret/1992/decreto-592-6-julho-1992-449004-publicacaooriginal-1-pe.html>. Acesso em: 6 maio 2018.

. Decreto n. 591, de 6 de julho de 1992. Atos Internacionais. Pacto Internacional sobre Direitos Econômicos, Sociais e Culturais. Promulgação. Presidência da República, Brasília, DF, 1992c. Disponível em: < http://www.planalto.gov.br/ccivil_03/decreto/1990-1994/d0591.htm>. Acesso em: 6 maio 2018.

. Câmara dos Deputados. Projeto Legislativo na Câmara dos Deputados. PEC no 368, de 7 de junho de 1996. Câmara, 1996. Disponível em: <http://www.camara.gov.br/ proposicoesWeb/fichadetramitacao?idProposicao $=24992>$. Acesso em: 6 maio 2018.

. Decreto $\mathrm{n}^{\mathrm{0}} 4.377$, de 13 de setembro de 2002. Promulga a Convenção sobre a Eliminação de Todas as Formas de Discriminação contra a Mulher, de 1979, e revoga o Decreto no 89.460, de 20 de março de 1984. Presidência da República, Brasília, DF, 2002. Disponível em: <http://www.planalto.gov.br/ccivil_03/decreto/2002/d4377.htm>. Acesso em: 6 maio 2018. 
. Emenda Constitucional $\mathrm{n}^{\mathrm{o}} 45$, de 30 de dezembro de 2004. Altera dispositivos dos arts. 5', 36, 52, 92, 93, 95, 98, 99, 102, 103, 104, 105, 107, 109, 111, 112, 114, 115, 125, 126, 127, 128, 129, 134 e 168 da Constituição Federal, e acrescenta os arts. 103-A, 103B, 111-A e 130-A, e dá outras providências. Presidência da República, Brasília, DF, 2004. Disponível em: <http://www.planalto.gov.br/ccivil_03/Constituicao/Emendas/Emc/ emc45.htm>. Acesso em: 6 maio 2018.

. Supremo Tribunal Federal. Súmula Vinculante n ${ }^{\circ} 25$. (Decorrente do julgamento dos Recursos Extraordinários RE 349703 e RE 466343 e Habeas Corpus HC 87585). In: . Súmulas. Brasília, DF, dezembro de 2008.

. Decreto ${ }^{0}$ 6.949, de 25 de agosto de 2009. Promulga a Convenção Internacional sobre os Direitos das Pessoas com Deficiência e seu Protocolo Facultativo, assinados em Nova York, em 30 de março de 2007. Presidência da República, Brasília, DF, 2007. Disponível em: <http://www.planalto.gov.br/ccivil_03/_ato2007-2010/2009/decreto/d6949. htm >. Acesso em: 6 maio 2018.

. Supremo Tribunal Federal. Coletânea temática de jurisprudência: Direitos humanos. Brasília: STF, Secretaria de Documentação, 2017. Disponível em: <http://www. stf.jus.br/arquivo/cms/publicacaoPublicacaoTematica/anexo/CTJ_Direitos_Humanos. pdf >. Acesso em: 6 maio 2018.

COMISSÃO INTERAMERICANA DE DIREITOS HUMANOS. Regulamento da Comissão Interamericana de Direitos Humanos. 2009. Disponível em: <http://www.oas. $\mathrm{org} / \mathrm{pt} / \mathrm{cidh} / \mathrm{mandato} / \mathrm{basicos} / \mathrm{reglamentocidh.asp}>$. Acesso em: 5 maio 2018.

CUNHA, José Ricardo. Direitos humanos e justiciabilidade: pesquisa no Tribunal de Justiça do Rio de Janeiro. Sur, Rev. Int. Direitos Human., São Paulo, v. 2 n. 3, p. 138-172, dez. 2005.

FERREIRA, Marcelo Ramos Peregrino; MEZZAROBA, Orides. O Direito Eleitoral Frente aos Tratados Internacionais - O Solipsismo da Jurisprudência Nacional e o Ativismo Pro Persona no Caso Mexicano. Revista Opinião Jurídica, Fortaleza, v. 16, n. 22, p. 156182, jan./jun. 2018.

FREEMAN, Michael. Humans Rights. Cambridge: sPolity Press, 2002.

GOMES, Luís Flávio. Estado constitucional de direito e a nova pirâmide jurídica. São Paulo: Premier, 2008.

GUZMAN, Manuel; VERSTAPPEN, Bert. What is monitoring: human rights information and documentation systems. Versoix [Switzerland]: HURIDOCS, 2001.

GUZMAN, Manuel; VERSTAPPEN, Bert; DUECK, Judith. Huridocs Events Standard Formats: a tool for documenting human rights violations. Versoix [Switzerland]: HURIDOCS, 2001. 
HUNT, Lynn. A invenção dos direitos humanos. São Paulo: Cia das Letras, 2009. JACARANDÁ, Rodolfo; PATRIOTA, Everaldo. Manual prático para atuação em direitos humanos. Brasília: Conselho Federal da Ordem dos Advogados do Brasil, 2016.

JACOBSEN, Anette Faye. Human Rights Monitoring: a field mission manual. Boston: Martinus Nijhoff Publishers and VSP, 2008.

KELSEN, Hans. Teoria pura do direito. São Paulo: Martins Fontes, 1998.

LEACH, Philip et al. Responding to systemic human rights violations: an analysis of 'pilot judgments' of the european court of human rights and their impact at national level. Antwerp: Intersentia, 2010.

MÆHLUM, Marit. Manual on Human Rights Monitoring: an introduction for human rights field officers. Norwegian Centre for Human Rights. Oslo: University of Oslo, 2006. MAUÉS, Antônio Moreira; MAGALHÃES, Breno Baía. A Recepção dos Tratados de Direitos Humanos pelos Tribunais Nacionais Sentenças Paradigmáticas de Colômbia, Argentina e Brasil. Revista Direito, Estado e Sociedade, Rio de Janeiro, n. 48 p. 76-112 jan./ jun. 2016.

MAZZUOLI, Valério. Teoria geral do controle de convencionalidade no direito brasileiro. Revista de Informação Legislativa, Brasília, v. 46, n. 181, p. 113-133, jan./mar. 2009.

MELO, Mario. Últimos avanços na justiciabilidade dos direitos indígenas no Sistema Interamericano de Direitos Humanos. Sur, Rev. int. direitos human., São Paulo, v. 3, n. 4, p. 30-47, jun. 2006.

MOREIRA, Thiago Oliveira. A aplicação dos tratados internacionais de direitos humanos pela jurisdição brasileira. Natal, RN: EDUFRN, 2015.

MOYN, Samuel. The Last Utopia: human rights in history. Cambridge: Harvard University Press, 2010.

ORGANIZAÇÃO DAS NAÇÕES UNIDAS. Declaração e programa de ação de Viena. In: CONFERÊNCIA MUNDIAL SOBRE DIREITOS HUMANOS, 1993, Viena. Portal de Direito Internacional, Viena, jun. 1993. Disponível em: <https://www.oas.org >. Acesso em: 6 maio 2018.

PETERKE, Sven. Manual Prático de Direitos Humanos Internacionais. Brasília: Escola Superior do Ministério Público da União, 2009.

PIOVESAN, Flávia. O Poder Judiciário e os Direitos Humanos. REVISTA USP, São Paulo, n. 101, p. 99-112, mar./abr./maio 2014.

RAMOS, André de Carvalho. Responsabilidade internacional por violação de direitos humanos: seus elementos, a reparação devida e sanções possíveis. Teoria e prática do direito internacional. São Paulo: Renovar, 2004. 
. O Diálogo das Cortes: o Supremo Tribunal Federal e a Corte Interamericana de Direitos Humanos. In: AMARAL JUNIOR, Alberto do; JUBILUT, Liliana Lyra (Org.). O STF e o Direito Internacional dos Direitos Humanos. São Paulo: Quartier Latin, 2009. . Teoria geral dos direitos humanos na ordem internacional. São Paulo: Saraiva, 2013. . Realizando a convergência entre o nacional e o internacional. In: PIOVESAN, Flávia; SALDANHA, Jânia Maria Lopes (Coord.). Diálogos Jurisdicionais e Direitos Humanos. Brasília: Gazeta Jurídica, 2016. p. 437-468.

RAWLS, John. O direito dos povos. São Paulo: Martins Fontes, 2001.

RAZ, Joseph. The Morality of Freedom. Oxford: Oxford University Press, 1986.

REZEK, Francisco. Direito Internacional Público. São Paulo: Saraiva, 2000.

ROTHENBURG, Walter Claudius. Diálogo internacional entre juízes: a influência do direito estrangeiro e do direito internacional na solução de casos de direitos fundamentais. In: MARINHO, Maria Edelvacy; SILVA, Solange Teles da; OLIVEIRA, Liziane Paixão Silva (Org.). Diálogos entre juízes. Brasília: UniCEUB, 2014. p. 39-55.

RUOTTI, Caren et al. Graves violações de direitos humanos e desigualdade no município de São Paulo. Rev. Saúde Pública, São Paulo, v. 43, n. 3, p. 533-540, jun. 2009.

SARLET, Ingo Wolfgang. Notas sobre as relações entre a Constituição Federal de 1988 e os tratados internacionais de direitos humanos na perspectiva do assim chamado controle de convencionalidade. In: MAZZUOLI, V. O.; MARINONI; L. G. (Coord.). Controle de convencionalidade: um panorama latinoamericano. Brasília: Gazeta Jurídica, 2013. p. 87- 114.

SARMENTO, Daniel. O Direito Constitucional e o Direito Internacional: diálogos e tensões. In: PIOVESAN, Flávia; SALDANHA, Jânia Maria Lopes (Coord.). Diálogos Jurisdicionais e Direitos Humanos. Brasília: Gazeta Jurídica, 2016. p. 93-138.

SILVA FILHO, Lídio Modesto da. Os juízes brasileiros e o controle de convencionalidade ambiental. Revista da AJURIS, Porto Alegre, v. 41, n. 135, p. 221-263, set. 2014.

UNITED NATIONS. A/RES/21/2200. Resolution adopted by the General Assembly. 2200 (XXI). International Covenant on Economic, Social and Cultural Rights, International Covenant on Civil and Political Rights and Optional Protocol to the International Covenant on Civil and Political Rights. UN Documents: Gathering a Body of Global Agreements, 16 Dec. 1966.

UNITED NATIONS. The International Bill of Human Rights. Office of the High Commissioner for Human Rights. UN Office of the High Commissioner for Human Rights (OHCHR), New York, Fact Sheet No. 2 (Rev.1), 1996.

UNITED NATIONS. Maastricht Guidelines on Violations of Economic, Social and Cultural Rights. MCHR 97124. Maastricht: University of Minnesota, 1997. 
UNITED NATIONS. Training Manual on Human Rights Monitoring. Professional Training Series, Genève, NY, n. 7, 2001.

UNITED NATIONS. The Human Rights Based Approach to Development Cooperation Towards a Common Understanding Among UN Agencies - Annex "B”: Human rightsbased approach. United Nations Development Group. New York, 2003.

UNITED NATIONS. Basic Principles and Guidelines on the Right to a Remedy and Reparation for Victims of Gross Violations of International Human Rights Law and Serious Violations of International Humanitarian Law. Resolution adopted by the General Assembly on 16 December 2005 [on the report of the Third Committee (A/60/509/Add.1)] 60/147. [S.1.: s.n.], 2005a.

UNITED NATIONS. Economic, Social and Cultural Rights. Handbook for National Human Rights Institutions. UN Office of the High Commissioner for Human Rights, New York, Geneva, n. 12, 2005 b.

UNITED NATIONS. Frequently asked questions on a human rights-based approach to development cooperation. Office of the High Commissioner for Human Rights. New York and Geneva, 2006.

UNITED NATIONS. Frequently Asked Questions on Economic, Social and Cultural Rights. Fact Sheet No. 33. Office of the High Commissioner for Human Rights. New York and Geneva, 2008a.

UNITED NATIONS. A Handbook for Civil Society. Working with the United Nations Human Rights Programme. HR/PUB/06/10/Rev.1. Office of the United Nations High Commissioner for Human Rights. New York and Geneva, 2008b.

UNITED NATIONS. Toolkit and guidance for preventing and managing land and natural resources conflict. United Nations Interagency Framework Team for Preventive Action. New York, 2010.

UNITED NATIONS. Manual on human rights monitoring. Office of the United Nations High Commissioner for Human Rights Methodology, Education and Training Section. Geneva, Switzerland, 2011.

UNITED NATIONS. Human Rights Indicators - A guide to measurement. HR/ PUB/12/5. Office of the High Commissioner for Human Rights. Geneva, NY, 2012a.

UNITED NATIONS. The United Nations Human Rights Treaty System. UN Office of the High Commissioner for Human Rights, New York, Fact Sheet No. 30 (Rev.1), 2012 b.

UNIVERSITÉ DE GENÈVE. What amounts to 'a serious violation of international human rights law'? an analysis of practice and expert opinion for the purpose of the 2013 Arms Trade Treaty. Academy Briefing, Geneva, n. 6, Geneva Academy of International Humanitarian Law and Human Rights, Aug. 2014. 